\title{
MARIO VARGAS LLOSA PREMIO NOBEL DE LITERATURA 2010
}

La historia del otorgamiento del Premio Nobel de Literatura es bien conocida y en ella podemos advertir, con los estupores del caso, injusticias notables, omisiones imperdonables, olvidos que podrían poner en duda la relevancia de este premio de carácter ecuménico. Felizmente tenemos, y son las más, premiaciones muy justas, reconocimientos que concitaron el acuerdo y el aplauso de todos en su momento y que no solo confirmaron la notable trayectoria del autor laureado, sino su lanzamiento a nivel universal. Nombres como los de Steinbeck, Camus o García Márquez nos devolvieron la fe en este premio y en lo que no debería dejar de ser nunca: la verdadera consagración de una obra, de notable calidad e importancia, y la de un escritor, ejemplo de conducta moral. Afortunadamente esto es lo que ha sucedido el 2010, al recaer el Premio Nobel en un escritor de nuestra casa, comprometido con su tiempo y con su obra como Mario Vargas Llosa, quien es, antes que nada, un hombre consecuente con sus ideas y creencias.

En este contexto de celebración y reconocimiento, la revista Letras desea sumarse a los merecidos homenajes que viene recibiendo nuestro notable escritor con la publicación, en este número, de algunos trabajos sobre su obra, en el entendido de que esa es la mejor manera de mostrar su valor y proyección, pero también desea rescatar, con la brevedad del caso, aquello que podría considerarse esencial en su concepción de la literatura y su valor. En este propósito, la conferencia magistral titulada "La literatura y la vida" que Vargas Llosa dictó en abril del 2001 con motivo del otorgamiento de la distinción universitaria de Profesor Honorario de la UPC, puede servirnos.

Esa conferencia es quizá una de las más convincentes y argumentadas disertaciones sobre la importancia y el poder de la literatura en estos tiempos, en los que se ha perdido la fe en la capacidad transformadora del arte. En esta conferencia, su devoción lo lleva a defender la idea de que la ficción puede mejorarnos como seres humanos y alejar de nosotros ciertos atavismos que solo consiguen separarnos violentamente. Vargas Llosa sostiene, en primer término, que es imprescindible combatir la idea de que la literatura aspire a ser solo un pasatiempo de lujo, una especie de divertimento que pudiera alegrar los fines de semana de un hombre desocupado o las inocuas reuniones de ingeniosas matronas interesadas en "cultivarse" en el arte de la palabra. Por el contrario, piensa que la literatura es una de las actividades más responsables y comprometidas con su tiempo y que tanto la escritura como la lectura de novelas demandan una vocación y un tiempo en los que el ser humano se vincula lúcida y efectivamente con su problemático contexto social. La literatura para Vargas Llosa no es evasión, es dramática inserción en nuestro tiempo.

Contra los escépticos, Vargas Llosa postula que la literatura puede luchar efectivamente contra la especialización del conocimiento y, por consiguiente, contra la fragmentación social, y contribuir con la función de hacer a los sujetos

LETRAS 81 (116), 2010 
más solidarios, más tolerantes. En este aspecto es bastante claro y su fe bastante convincente: la literatura pude constituirse en un espacio o un denominador común de la especie. Nada, nos dice, enseña mejor que la literatura a ver en las diferencias étnicas y culturales, la gran riqueza del patrimonio humano y a valorarlas como manifestación de su múltiple creatividad.

El convencimiento de que una comunidad sin literatura jamás llegará a alcanzar un nivel de expresión alto, anima, también, a Vargas Llosa a pensar que las sociedades que no leen o que no producen escritores constituyen un conglomerado de afásicos incapaces de comunicarse y, por lo tanto, de agenciar un espacio para la discusión, para el debate de ideas.

Otro argumento importante, presentado por Vargas Llosa a favor de la defensa del valor y de la utilidad de la literatura, es que nos permite cultivar una conciencia crítica y responsable sobre nuestra sociedad, dado que toda novela incorpora en su discurso un cuestionamiento del mundo en que vivimos. Vargas Llosa sustenta esta idea en el hecho de que existe una inconformidad de base en los seres humanos y que esta inconformidad propicia el desarrollo, el cambio social desde las raíces mismas del individuo. Contra la idea del respeto y sujeción a lo establecido, la literatura nos muestra la posibilidad de la rebelión permanente, consustancial al hombre libre.

De otro lado, Vargas Llosa se muestra convencido de que la literatura puede liberarnos de nuestra sujeción a los mandatos de una opaca y a veces estéril realidad y nos invita a vivir en mundos desconocidos en los que podemos ser otros, comprendiendo a los otros. La experiencia de lectura de los textos de Borges, por ejemplo, nos prueba que los límites que nos imponen las convenciones en las que se funda nuestro conocimiento del mundo son fácilmente destruibles desde el inconmensurable espacio de la imaginación, de lo posible.

Para terminar, destaquemos la gran importancia que para Vargas Llosa tiene la ficción en el propósito de formar ciudadanos libres en una sociedad moderna y democrática, y las ventajas de la literatura para propiciar el diálogo entre los seres humanos. Es claro para nuestro escritor que la literatura fomenta, a partir del ejercicio de la creación y de la lectura, valores como la democracia y el respeto a los demás en la medida en que solo puede concebirse a un escritor como un ser absolutamente libre y a su obra como expresión de esa libertad. La confianza de Vargas Llosa en la literatura para hacer de los hombres seres más tolerantes y menos crueles parte de estos supuestos y se constituye en una bella apuesta que, a pesar de ser un deseo lanzado al futuro, merece ser defendida por todos los que creemos en el poder de las palabras, en la gravedad e importancia del lenguaje, ese instrumento que nos hace humanos y nos aleja del mundo de los animales.

En suma, un mundo sin literatura para Vargas Llosa sería un mundo, como él mismo lo dice, incivil, bárbaro, huérfano de sensibilidad y torpe de habla, ignorante y ventral, negado para la pasión y el erotismo, un mundo viciado de conformidad y sometido a los dictámenes del poder. Ese poder cuya naturaleza siempre es una amenaza para los seres humanos, ese poder que debemos combatir todos los días de nuestras vidas (Jorge Valenzuela Garcés). 